\title{
Radiotherapy of Esophageal Carcinomas at the Dantec University Hospital of Dakar from 2010 to 2015
}

\author{
Papa Macoumba Gaye1, Mouhamadou Bachir Ba1, Dabbo Dieng1, \\ Mamadou Moustapha Dieng', Ahmadou Dem² \\ ${ }^{1}$ Radiotherapy Department, Dalal Jamm Hospital, Dakar, Sénégal \\ ${ }^{2}$ Joliot Curie Institute, Dakar, Senegal \\ Email: Macoumba.gaye@gmail.com, mbbachir21@gmail.com, dabbodieng@gmail.com, \\ moustaphamamadou@gmail.com, Adehdem@gmail.com
}

How to cite this paper: Gaye, P.M., Ba, M.B., Dieng, D., Dieng, M.M. and Dem, A. (2020) Radiotherapy of Esophageal Carcinomas at the Dantec University Hospital of Dakar from 2010 to 2015. Journal of Cancer Therapy, 11, 324-331. https://doi.org/10.4236/jct.2020.115026

Received: September 30, 2018

Accepted: May 16, 2020

Published: May 19, 2020

\section{Copyright $\odot 2020$ by author(s) and} Scientific Research Publishing Inc. This work is licensed under the Creative Commons Attribution International License (CC BY 4.0).

http://creativecommons.org/licenses/by/4.0/ (c) (i) Open Access

\begin{abstract}
We performed a descriptive retrospective study of radiotherapy of esophageal carcinomas at the Dantec University Hospital in Dakar from 2010 to 2015. The aim was to describe the type of patient, and to evaluate the indication and the results of the irradiation. We consulted 117 cases and selected 26 cases. The average age of patients is 46.1 years (Extremes 17 - 83 years and peaks $30-39$ and 50 - 59 years). The sex ratio is 1.67 . Smoking was reported in $38.4 \%$ of cases and alcoholism in $15.3 \%$. Dysphagia is the predominant sign $(100 \%$ of patients). The general condition is classified WHO 1 for $42.3 \%$ of cases. The tumor was localized in $61.5 \%$ in the lower third and is stenosing in $84.6 \%$ of our patients. Squamous cell carcinoma is the most common type (88.5\% of cases). The size of the tumor, specified in $50 \%$ of cases, varies from 2.6 to 11.2 $\mathrm{cm}$. Computed tomography is performed in more than $50 \%$ of cases. Endoscopic ultrasonography is not performed and surgical exploration has contributed to the staging of $7.7 \%$ of irradiated patients. The tumor is localized in $47.8 \%$ of cases; at an advanced stage in $52 \%$ and is metastatic in $4.3 \%$. We note a transhiatal excision and a gastrostomy in $15 \%$ and $69 \%$ of the cases and no surgery of excision in healthy margin. Chemotherapy or neoadjuvant radiotherapy is not performed. The radiotherapy was: exclusive (11\%), adjuvant after surgery in margin R2 (15\%), palliative in $3 \times 5$ Gy per 3 week (4\%) and concomitant with chemotherapy cisplatyl 5FU (70\%). The spread ranges from 2 to 6 weeks. The partial and complete response rate is $38.4 \%$ and $11.5 \%$. The stabilization is $30.7 \%$ and the progression is $19.4 \%$. Grade I-2 toxicity was noted in $46.1 \%$ (asthenia, radiodermatitis, cough) and grade 3 radiodermite in $4 \%$. The average follow-up time is 198.19 days with extremes
\end{abstract}


of 2 days and 32 months.

\section{Keywords}

Radiotherapy, Esophageal, Sénégal

\section{Introduction}

Esophageal cancer is classically a squamous cell carcinoma occurring in an alcohol-smoking man [1].

Its discovery, often late, largely explains its poor prognosis, with an overall survival at 5 years of less than $10 \%$ [2].

Its treatment is transdisciplinary. It uses 3 main modalities: surgery, chemotherapy and radiotherapy.

Curative surgical excision is the treatment of early stages. It is possible in less than $5 \%$ of cases in Dakar because of an advanced stage of diagnosis [3]. Radiation therapy is then the locoregional treatment of choice.

We evaluate radiotherapy of esophageal carcinomas at the Joliot Curie Institute of The dantec University Hospital of Dakar between 2010 and 2015 in a descriptive retrospective study.

\section{Patients and Methods}

\subsection{Study Framework}

Our study is carried out at the Joliot Curie Institute of CHU, the Dantec of Dakar.

It is equipped with hospitalization units, chemotherapy, an operating theatre and a cobalt therapy facility.

\subsubsection{Objectives of the Study}

This is a descriptive retrospective study whose objective is to describe the type of patient received, to evaluate the indication and the results of the irradiation.

\subsubsection{Study Population}

We selected the cases among:

- Patients who have been received at Aristide Le Dantec Hospital in the departments of internal medicine, general surgery and cancer institute.

- And with histopathologically confirmed esophageal carcinoma.

- And whose files are recovered.

\subsubsection{Criteria for Inclusion}

We included patients who received radiotherapy treatment.

\subsubsection{Criteria for Non-Inclusion}

We did not include:

- Patients with esophageal extension VADS cancers.

- Cardiac cancers with esophageal extension. 


\subsubsection{Parameters Studied}

We studied the epidemiological, clinical, paraclinical and therapeutic parameters of the different patients.

\subsection{Methods of Collection}

The data are collected on a farm return. We use the TNM UICC 2010 classification.

Patients who did not benefit from an extension assessment were classified Tx.

Response was assessed by clinical examination, endoscopy and/or CT scan.

All new tumors within $3 \mathrm{~cm}$ of the initial tumor bed, with the same histology and occurring more than 6 months after treatment and progressive continuation, were considered local recurrence as new lesions in the esophagus within 6 months of the end of treatment.

Survival is defined here by the time interval between the date of the first consultation and the date of the last consultation.

Patients lost to follow-up with progressive disease are considered as patients who have died of a progressive disease.

\section{Methods of Analysis}

Data entry and analysis were performed with Excel software.

We also compared epidemiological, clinical, paraclinical and therapeutic data from patients with esophageal carcinoma who had or had not received radiotherapy.

\section{Results}

The average age of irradiated patients is 46.1 years with extremes of 17 and 83 years. The sex ratio is 1.67. The two most represented age groups were 30 - 39 years and $50-59$ years. Smoking is noted in $38.4 \%$ of patients and alcoholism in $15.3 \%$.

Dysphagia is the predominant sign (100\% of patients) (Figure 1). The tumor was localized in $61.5 \%$ of cases in the lower third and is stenotic in $84.6 \%$ of our patients.

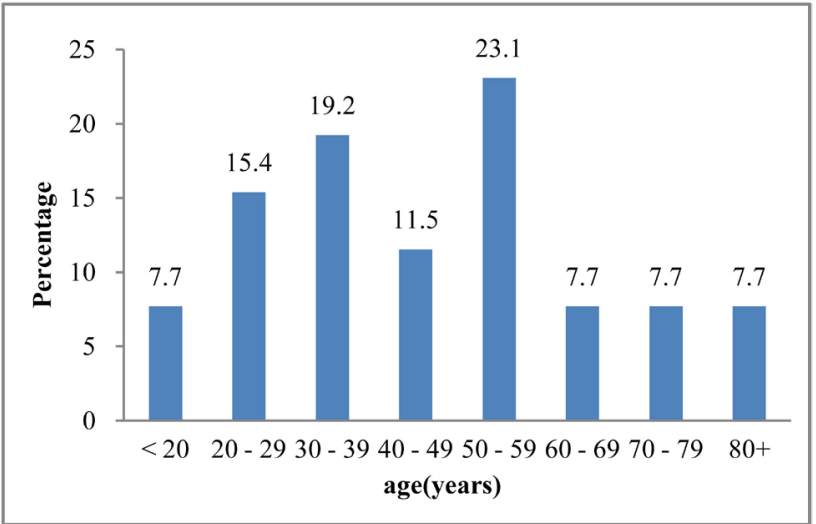

Figure 1. Age distribution. 
Squamous cell carcinoma is the most frequent histological type (88.5\% of cases). The size of the tumor, specified in $50 \%$ of cases, varies from 2.6 to $11.2 \mathrm{~cm}$.

The CT scan is performed in more than $50 \%$ of cases. Echoendoscopy is not performed and surgical exploration was involved in staging $7.7 \%$ of irradiated patients. The tumor is localized in $47.8 \%$ of cases; advanced in $52 \%$ and metastatic in $4.3 \%$.

It was noted that $7.6 \%$ of irradiated patients did not benefit from an extension assessment.

Radiation therapy consisted of external irradiation with a $2 \mathrm{D}$ technique using cobalt-60 after conventional simulation and 2D dosimetry.

Conformational radiotherapy and $3 \mathrm{D}$ dosimetry were not available during our study period.

The doses received are distributed as follows:

- 15 Gy in 3 fractions/1 time per week: 1 case.

- $30 \mathrm{~Gy}$ in 10 fractions/5 times per week: 13 cases.

- $40 \mathrm{~Gy}$ in 20 fractions/5 times per week: 12 cases.

We note that 4 patients had transhiatal surgery (15\%) in the invaded margin and none had healthy margin excision surgery. We note in 18 patients a gastrostomy of food (69\%).

None of our patients have received chemotherapy or neoadjuvant radiotherapy.

In our series, 3 patients received exclusive radiotherapy (11.5\%) whose dose did not exceed 40 Gy; 4 received adjuvant radiotherapy after R2 margin surgery (15\%). One patient received palliative radiotherapy (4\%) at a dose of $15 \mathrm{~Gy}$ in 3 fractions at a rate of one fraction per week.

We performed for $19 \%$ of patients' concomitant radiotherapy $(10 \times 3$ Gy or 20 $\times 2 \mathrm{~Gy}$ ) and chemotherapy (cisplatyl $100 \mathrm{mg} / \mathrm{m}^{2} \mathrm{~J} 1$ and $5 \mathrm{FU} 300 \mathrm{mg} / \mathrm{m}^{2} \mathrm{~J} 1$ in $1^{\text {st }}$ and $4^{\text {th }}$ week).

The spreading of the treatments that we carried out varies from 2 to 6 weeks

We obtain a partial response rate of $38.4 \%$ and a complete response rate of $11.5 \%$ in all irradiated patients. There was stability in $30.7 \%$ of irradiated patients. The growth rate was $19.4 \%$.

Grade 2 toxicity is noted in $46.1 \%$ of cases. These are: asthenia, tracheoesophageal fistula, radiodermatitis, cough and vomiting.

The average follow-up time is 198.19 days (extremes of 2 days and 32 months). There were $84.6 \%$ lost to follow-up

These results were compared to those of patients with esophageal carcinoma who received no radiotherapy at The Dantec UHC during the same period (Table 1).

\section{Discussion}

\subsection{Epidemiology}

The irradiated population represents only $27.3 \%$ of the patients received at CHU the Dantec. These patients who are not referred benefit more often from 
Table 1. Summary of diagnostic evidence and treatment outcomes.

\begin{tabular}{ccc}
\hline Results obtained & Irradiated & Not irradiated \\
\hline Average age & 46.1 & 43.9 \\
Sex ratio & 1.67 & 1.64 \\
Dysphagia & $96.1 \%$ & $100 \%$ \\
WHO1 & $42.3 \%$ & $38.1 \%$ \\
WHO3 & $15 \%$ & $15 \%$ \\
Location (1/3 lower) & $61.5 \%$ & $60 \%$ \\
Accuracy of the size & $50 \%$ & $40 \%$ \\
TDM & $92.3 \%$ & $87 \%$ \\
Bronchial endoscopy & $3.85 \%$ & $7.25 \%$ \\
Surgical exploration & $7.62 \%$ & $2.9 \%$ \\
Metastatic & $4.3 \%$ & $30.2 \%$ \\
Full response & $11.53 \%$ & $5.79 \%$ \\
Partial Response & $38.4 \%$ & $11.6 \%$ \\
Stability & $30.7 \%$ & $4.34 \%$ \\
Increase & $19.37 \%$ & $78.27 \%$ \\
\hline
\end{tabular}

gastrostomy bypass surgery ( $73 \%$ versus $69 \%)$ in the services concerned without any other specific treatment.

In Senegal, the average age of patients is 48 years [4]. The young age of the patients ( $2 \%$ are less than 20 years old) could be linked to infectious factors or chronic anaemia.

The sex ratio of our patients is no different from that of the world literature [5]. It does not seem to intervene in the indication of external radiotherapy (identical sex ratio of 1.67).

The low rate of alcohol and tobacco intoxication could be explained by the socio-cultural and religious context.

We were unable to provide a history of achalasia and endobrachy-esophagus. In the Aggestrup study, 10 of 23 patients with achalasia had an esophageal tumor [6].

The study of epidemiological factors is strongly hampered by the absence of a national cancer registry.

\subsection{Diagnosis}

In our study, $60 \%$ of tumors were located in the lower third of the esophagus. This rate is $56.26 \%$ in Madagascar [7].

The tumor was stenosing in $84.6 \%$ and $88 \%$ of irradiated and non-irradiated patients, respectively. The systematic indication of irradiation of stenosis patients is retained in the literature [7].

The improvement of the general condition is one of the major decision ele- 
ments for cobalt therapy in Dakar.

The histopathological study shows $88.5 \%$ squamous cell carcinoma in irradiated patients. This rate is higher in the unirradiated population (92.7\%).

CT scans, performed in more than $50 \%$ of our patients, play a major role in the assessment of the spread of esophageal cancer.

No patients received IRM. Its spatial resolution is lower than that of the scanner [8].

Surgical exploration at the time of gastrostomy was involved in staging our irradiated patients in $7.7 \%$ of cases versus $3 \%$ of non-irradiated patients.

Among irradiated patients, $47.8 \%$ had localized cancer. Only $4.3 \%$ had metastatic cancer compared to $30 \%$ of non-irradiated patients.

\subsection{Treatment}

The standard treatment for an esophageal tumor is surgical. The main objective of chemotherapy prescription is to reduce tumor size or increase resectability.

Kelsen et al. [9], is compared surgery to 3 cycles of CDDP 5-FU before surgery, on 461 patients. This study showed no difference in survival after 55 months of decline. None of our patients have received neoadjuvant chemotherapy. It may be recommended in patients with adenocarcinoma [10].

None of the irradiated patients underwent excision surgery.

Thus, $69.23 \%$ of the study population had a gastrostomy diet.

Surgery in the advanced stages gives a survival at 5 years of $10 \%$ to $17 \%$ [11].

Radiation therapy was the only alternative to surgery until the late 1980s in inoperable patients.

Exclusive RTE is still indicated in palliative situations. It is effective on dysphagia in $80 \%$ of cases with an average response time of 6 to 10 months. The survival rate at 5 years after exclusive curative RTE varies between $3 \%$ and $6 \%$ [9].

The alternative to palliative RTE is high dose rate brachytherapy. She's not available in our department. However, the quality of endoluminal clearance obtained is not good and this type of palliative treatment cannot currently be recommended [12].

The benefit of radiosurgical combination, in the absence of chemotherapy, is marginal on survival [13] [14].

Post-operative radiotherapy has been replaced in recent years by concomitant adjuvant radiochemotherapy [15].

Total treatment duration is a predictor of response. Bifractionated radiotherapy ( 2 sessions per day) allows to reduce this time and to obtain an improvement of the local control rate at 2 years, but its implementation is difficult in our context. In addition, many trials have shown a superiority of RCT over exclusive RT. Three randomized trials compared concomitant preoperative RCT with exclusive surgery. The study published by Walsh is the only positive study. The major criticism of this trial is the poor survival in the surgical arm at 3 years 
[16].

Le Prized et al. [17] compared exclusive surgery with sequential RCT (2 CDDP/5-FU cures then 20 Gy/10fr. then the same 2 CT cures). The complete histologic response rate in the RTCT arm was $11 \%$. The survival difference was not significant (14\% versus $19 \%$ at 3 years) but the RT pattern was probably not optimal.

The trial published by Bosset et al. [18], compared in 297 patients with squamous cell carcinomas, surgery versus 2 times $18 \mathrm{~Gy}$ associated with Cisplatin. In this trial, average survival and 3-year survival are almost superimposed. However, there was a significant increase in DFS $(p=0.003)$ in the preoperative RCT arm and a decrease in cancer deaths $(\mathrm{p}=0.002)$. This trial showed an excess mortality in the TCR arm (12.6\% versus $3.6 \%)$ probably related to sepsis and acute respiratory failure with doses of $3.5 \mathrm{~Gy}$ per fraction

\section{Conclusions}

The diagnostic evaluation of our patients, often young and rarely alcohol-smoking, remains insufficient.

The indications for radiotherapy in esophageal cancer could be improved in our practice through better collaboration.

The development of modern diagnostic and radiotherapy techniques could bring better therapeutic results.

\section{Conflicts of Interest}

The authors declare that they have no conflicts of interest in relation to this article.

\section{References}

[1] Faivre, J., Forman, D., Estève, J., Gatta, G. and the EUROCARE Working Group (1998) Survival of Patients with Oesophageal and Gastric Cancers in Europe, 1985-1989. European Journal of Cancer, 34, 2167-2175. https://doi.org/10.1016/S0959-8049(98)00329-3

[2] Sjogren, R.W. and Johson, L.F. (1983) Barrett's Oesophagus. The American Journal of Medicine, 74, 313-321. https://doi.org/10.1016/0002-9343(83)90635-6

[3] Triboulet, J.P. (1999) Cancer de l'œsophage: Epidemiologie, étiologie, diagnostic. EMC Hépato-Gastroentérologie, 49, 635-638.

[4] Diop, P.S., Ndoye, J.M., Ndiaye, D., et al. (2009) Cancer de l'oesophage au Sénégal: Revue d'une série de 72 cas. Journal Africain d Hépato-Gastroentérologie, 3, 190-194. https://doi.org/10.1007/s12157-009-0115-8

[5] Madebo, T., Lindtjorn, B. and Henriksen, T.H. (1994) High Incidence of Esophagus and Stomach Cancers in the Bale Highlands of South Ethiopia. Transactions of the Royal Society of Tropical Medicine and Hygiene, 88, 415. https://doi.org/10.1016/0035-9203(94)90407-3

[6] Aggetsrup, S., Holm, J.C. and Sorensen, H.R. (1992) Does Achalasia Predispose to Cancer of the Oesophagus. Chest, 102, 1013-1016.

https://doi.org/10.1378/chest.102.4.1013 
[7] Peghini, M., Rajaonarison, P., Pecarrere, J.L., et al. (1997) Epidémiologie des cancers du tube digestif à Madagascar. Médecine d' Afrique Noire, 44, 519-521.

[8] Schmutz, G., Fournier, L., Le Pennec, V. and Billiard, J.S. (2004) Pathologie de l'œsophage, l'imagerie en coupe a-t-elle un intérêt? Journal de Radiologie, 85, 478-499. https://doi.org/10.1016/S0221-0363(04)97620-2

[9] Kelsen, D.P., Ginsberg, R., Pajak, T.F., et al. (1998) Chemotherapy Followed by Surgery Compared with Surgery Alone for Localized Esophageal Cancer. The New England Journal of Medicine, 339, 1979-1984. https://doi.org/10.1056/NEJM199812313392704

[10] MRC Oesophageal Working Group (2002) Surgical Resection with or without Preoperative Chemotherapy in Oesophageal Cancer: A Randomised Controlled Trial. The Lancet, 359, 1727-1733. https://doi.org/10.1016/S0140-6736(02)08651-8

[11] Orringer, M.B., Marshall, B. and Stirling, M.C. (1993) Transhiatal Esophagectomy for Benign and Malignant Disease. The Journal of Thoracic and Cardiovascular Surgery, 105, 265-276. https://doi.org/10.1016/S0022-5223(19)33811-5

[12] Bedenne, L., Faivre, J., Boutron, M.C., et al. (1986) Cancer of the Esophagus in the Department of Cote-d'Or. Bulletin du Cancer, 73, 526-534.

[13] Calais, G. (2011) Cancers de l'œsophage in Techniques d'irradiation des cancers, La radiothérapie conformationnelle, Maloine 2011/255.

[14] Ajani, J.A. (1994) Contributions of Chemotherapy in the Treatment of Carcinoma of the Esophagus: Results and Commentary. Seminars in Oncology, 21, 474-482.

[15] Fok, M., Sham, J.S., Choy, D., et al. (1993) Postoperative Radiotherapy for Carcinoma of the Esophagus: A Prospective, Randomized Controlled Study. Surgery, 113, 138-147.

[16] Walsh, T.N., Noonan, N., Hollywood, D., et al. (1996) A Comparison of Multimodal Therapy and Surgery for Esophageal Adenocarcinoma. The New England Journal of Medicine, 335, 462-467. https://doi.org/10.1056/NEJM199608153350702

[17] Le Prise, E., Etienne, P.L., Meunier, B., et al. (1994) A Randomized Study of Chemotherapy, Radiation Therapy, and Surgery versus Surgery for Localized Squamous Cell Carcinoma of the Esophagus. Cancer, 73, 1779-1784. https://doi.org/10.1002/1097-0142(19940401)73:7<1779::AID-CNCR2820730702>3. $\underline{0 . \mathrm{CO} ; 2-\mathrm{T}}$

[18] Bosset, J.F., Gignoux, M., Triboulet, J.P., et al. (1997) Chemoradiotherapy Followed by Surgery Compared with Surgery Alone in Squamous-Cell Cancer of the Esophagus. The New England Journal of Medicine, 337, 161-167. https://doi.org/10.1056/NEJM199707173370304 